\title{
Fatores Associados ao Desempenho Escolar: Estudo Multinível com Dados do SAEB/2001 ${ }^{1}$
}

\author{
Josemberg M. de Andrade ${ }^{2}$ \\ Jacob A. Laros \\ Universidade de Brasília
}

\begin{abstract}
RESUMO - Esse estudo visou construir um modelo de desempenho escolar utilizando análise multinível, um tipo de regressão múltipla que leva em consideração a estrutura hierárquica dos dados. Foram considerados os dados do SAEB de 2001, especificamente os referentes aos alunos da $3^{a}$ série do Ensino Médio. Depois de controlar o efeito das variáveis de seletividade e composição escolar verificou-se uma correlação intraclasse de 0,17 . Isso significa que $17 \%$ da variância no desempenho escolar podem ser atribuídos ao nível da escola. No modelo multinível final foram incluídas sete variáveis referentes ao aluno e nove variáveis referentes à escola. As variáveis com efeito mais forte concernentes ao aluno foram: atraso escolar e comparação do aluno com os colegas. Quanto à escola foram: recursos culturais agregado e atraso escolar agregado. Espera-se que o modelo final seja utilizado para a elaboração de políticas públicas visando o melhoramento do sistema educacional brasileiro.
\end{abstract}

Palavras-chave: desempenho escolar; avaliação educacional; análise de regressão multinível; SAEB.

\section{Factors Associated with School Performance: a Multilevel Study with Data of SAEB/2001}

\begin{abstract}
The purpose of this study was to construct a model of student performance using multilevel analysis, a type of multiple regression that takes into consideration the hierarchical structure of the data. The study used the data of the third grade students of secondary school who participated in the SAEB 2001 assessment. After controlling the effect of the variables of selectivity and school composition, an intraclass correlation of 0.17 was found, indicating that $17 \%$ of the variance in student performance can be attributed to the school level. In the final multilevel model seven variables of student level and nine variables of school level were included. The variables with the strongest effect on student level were: school delay and comparison of the student with his colleagues. On school level these variables were: aggregated cultural resources and aggregated school delay. The final model elaborated in this study will hopefully be used to elaborate public policies with a view to improve the Brazilian educational system.
\end{abstract}

Key words: student performance; educational evaluation; multilevel regression analysis; SAEB.

A avaliação está presente em várias instâncias da ação humana e, especificamente no processo educacional, pode efetivar melhorias no processo ensino-aprendizagem (Mello \& cols., 2001). Embora a cultura de avaliação educacional esteja em vias de desenvolvimento no Brasil, é perceptível o avanço empreendido nessa área, seja por meio dos recursos metodológicos de que se dispõe, seja por meio das avaliações que vêm sendo operacionalizadas (Rodrigues, 2002). A avaliação realizada pelo professor, no âmbito escolar, pode ser compreendida como uma das etapas do processo ensino-aprendizagem, na medida em que diagnostica as necessidades, os interesses e os problemas dos alunos. É a partir dos resultados observados que os professores podem planejar atividades de ensino mais adequadas às necessida-

1 Este artigo é baseado na dissertação de mestrado do primeiro autor sob a orientação do segundo autor e apresentado ao programa de Pós-Graduação em Psicologia da UnB. Os autores agradecem o apoio financeiro do CNPq.

2 Endereço: SHIN CA 02 Lote F, Lago Norte, Brasília, DF, Brasil 71505-000.E-mail: josemberg@unb.br des dos alunos. A avaliação educacional em larga escala, por sua vez, é operacionalizada com finalidade similar, ou seja, fornece elementos para subsidiar políticas e diretrizes adequadas à realidade educacional nos contextos municipal, estadual e nacional (INEP, 2001a).

No processo avaliativo também se deve considerar que o desempenho dos avaliados precisa ser contextualizado. Isto é relevante uma vez que as desigualdades sociais têm implicações diretas sobre a educação (INEP, 2001b). Como assinala Jesus (2004), variáveis internas e externas à escola podem estar associadas ao desempenho escolar dos alunos. Como indicam Franco e Bonamino (2001) em relação ao Sistema de Avaliação da Educação Básica (SAEB), as iniciativas de avaliações de sistemas educacionais envolvem questões centrais para as práticas educacionais, e a construção de modelos explicativos do desempenho escolar é um desafio. A identificação dessas variáveis é útil para a elaboração de políticas públicas que possam melhorar a qualidade da educação brasileira (Soares, César \& Mambrini, 2001). Embora seja evidente que as condições socioeconômicas dos alunos influenciam diretamente o desempenho acadêmico, constata-se, todavia, que a escola também faz 
diferença. Esse fato é verificado uma vez que alunos oriundos de um mesmo contexto socioeconômico podem apresentar desempenho escolar diferenciado em razão de estudarem em escolas distintas. Dessa forma, não existe um determinismo absoluto (INEP, 2001b).

$\mathrm{Na}$ identificação das variáveis relacionadas ao desempenho escolar deve-se conceber que as estruturas educacionais são construídas em torno de grupos de indivíduos, sejam eles famílias, escolas, bairros ou grupos de amigos. A partir desses agrupamentos, os indivíduos compartilham opiniões, atitudes ou realizações (Ferrão, 2003; Goldstein, 2001). Assim, pode-se dizer que o desempenho escolar é determinado por diversos fatores (Barbosa \& Fernandes, 2001; Lüdke, 2001) e depende do que o aluno traz consigo, bem como daquilo que a escola oferece em termos de ensino, de instalações e de ambiente. Caso se queira pesquisar a complexidade de fatores relacionados ao desempenho escolar, é preciso utilizar instrumentos de modelagem, que envolvam um nível comparável de complexidade. No entanto, mesmo dispondo desses instrumentos, dificilmente se chegará a descrições totalmente fidedignas da realidade (Goldstein, 2001).

Uma metodologia estatística que pode ser utilizada para esse fim é a análise de regressão múltipla. Essa técnica consiste na determinação de um modelo matemático que visa descrever o relacionamento entre variáveis (Soares \& cols., 2001). Todavia, os procedimentos estatísticos tradicionais, como esse tipo de análise, tratam os indivíduos como entidades que atuam independentemente da filiação ou da estrutura grupal em que estão inseridos e, assim, os possíveis efeitos das influências dessas estruturas são ignorados. Isso leva, possivelmente, a conclusões distorcidas da realidade (Goldstein, 2001). Diante dessas limitações, o uso de análises de regressão multinível apresenta vantagens práticas. Basicamente, nesse tipo de análise são considerados os níveis em que as variáveis estão inseridas (Kreft \& De Leeuw, 1998; Natis, 2001; Snijders \& Bosker, 1999).

Além do uso da análise de regressão multinível como um dos principais requisitos metodológicos nos estudos sobre eficácia escolar, Ferrão (2003) assinala que esses estudos devem identificar os fatores extra e intra-escolares associados ao bom desempenho do aluno. Interessa identificar, principalmente, os fatores passíveis de intervenção e que possam trazer melhorias para o sistema educacional.

Diante da relevância de se estudar variáveis relacionadas ao desempenho escolar e considerando a análise de regressão multinível como a técnica estatística mais adequada para dados com estrutura hierárquica, o presente estudo tem como objetivo construir um modelo de desempenho escolar. Em outras palavras, pretende-se verificar quais as características dos agentes envolvidos (alunos, pais, professores, diretores) e das escolas que justificam diferenças no desempenho escolar dos alunos.

Diante da complexidade dos temas aqui tratados, é feita uma breve exposição sobre análise de regressão multinível, bem como sobre variáveis contextuais relacionadas ao desempenho escolar. O interesse não é de esgotar esses temas, e sim caracterizá-los, a fim de se obter uma melhor compreensão dos resultados apresentados a posteriori.

\section{Análise de Regressão Multinível}

Os indivíduos são influenciados pelo grupo social a que pertencem e as propriedades desses grupos também influenciam os próprios indivíduos. Dessa forma, pode-se considerar que indivíduos e grupos são níveis separados de um sistema hierárquico (Hox, 2002). Estruturas hierárquicas de dados são encontradas freqüentemente em diversos estudos nas ciências sociais, sendo caracterizadas pela presença de unidades agrupadas em unidades ainda maiores, que, por sua vez, também podem ou não formar novos grupos (Natis, 2001). Este tipo de estrutura é comum em sistemas educacionais, em que se têm estudantes agrupados em classes, que, por sua vez, estão agrupadas em escolas e assim por diante. Como já assinalado, dados hierárquicos podem ser estudados por meio da análise de regressão multinível.

Nesse tipo de análise são verificadas as contribuições das variáveis considerando-se os níveis em que estão inseridas. O modelo de regressão multinível incorpora, naturalmente e de maneira parcimoniosa, a estrutura hierárquica dos dados, tratando o intercepto e os coeficientes de inclinação como variáveis aleatórias (Ferrão, 2003). Isso significa que cada unidade do segundo nível pode ter seu próprio valor.

Nas análises multinível deve-se especificar a que nível a variável pertence e quais os efeitos diretos, bem como quais os efeitos de interação entre os níveis que são esperados. Em relação à medição das variáveis, estas podem ser feitas diretamente no próprio nível da variável e, também, por agregação ou desagregação. Agregar significa que uma variável de um nível mais baixo será movida para um nível mais elevado. Desagregar, por outro lado, significa mover variáveis de um nível mais alto para um nível mais baixo (Hox, 2002).

Os modelos multinível mais utilizados são o de componentes de variância e o de coeficientes aleatórios. No primeiro desses, apenas o intercepto é aleatório e a variância da variável dependente é decomposta entre os níveis. Já no segundo modelo, testa-se o efeito randômico dos coeficientes de inclinação (Ferrão, 2003; Hox, 2002). O modelo de regressão multinível com interceptos randômicos é apresentado na equação a seguir (Hox, 2002). Neste, o nível 1 refere-se aos alunos, o nível 2 à escola e, por fim, a variável dependente é o desempenho escolar dos estudantes.

$$
\begin{aligned}
& Y_{i j}=\beta_{o j}+\beta_{l j} X_{l j}+e_{i j} \text { onde: } \\
& \beta_{o j}=\gamma_{o 0}+\gamma_{o 1} Z_{l j}+U_{o j} \\
& \beta_{l j}=\gamma_{10}
\end{aligned}
$$

$Y_{i j}=$ desempenho escolar do estudante $i$ na escola $j$;

$\beta_{o j}^{i j}=$ intercepto, ou seja, valor médio do desempenho escolar dos estudantes quando $X_{l j}$ é zero;

$X_{1 j}=$ primeira variável explicativa do nível 1 a entrar no modelo;

$\beta_{1 j}=$ coeficiente de inclinação, também chamado de coeficiente de regressão, que é a mudança esperada no desempenho escolar quando $X_{1 j}$ aumenta uma unidade;

$e_{i j}=$ resíduo do nível 1 , ou seja, parte do desempenho escolar não explicado pelo modelo;

$\gamma_{00}=$ média de interceptos de $j$ escolas;

$U_{o j}=$ variância residual do nível 2 ;

$Z_{1 j}^{o j}=$ primeira variável explicativa do nível 2 a entrar no modelo; 
$\gamma_{10}=$ média de coeficientes de regressão de $j$ escolas para a primeira variável do nível 1 .

Vale ressaltar que a diferença entre o modelo de regressão tradicional e o de regressão múltipla é que, neste último, assume-se que cada escola tem intercepto e inclinação diferentes. Isso é indicado por meio da inserção do subscrito $j$ (Hox, 2002). Este subscrito no intercepto significa que existe um intercepto diferente para cada escola.

\section{A relação do desempenho escolar com variáveis contextuais}

O desempenho escolar do aluno é resultante de uma complexa interação entre vários fatores que atuam simultaneamente em diversos níveis da inserção social (Barbosa \& Fernandes, 2001). Na literatura pertinente, algumas variáveis são relacionadas com o desempenho escolar. Por exemplo, verificou-se que no SAEB de 1997 os alunos com melhor condição socioeconômica, trajetória escolar regular, do sexo masculino e que estudam em escolas particulares são aqueles com melhor desempenho em Matemática (Soares \& cols., 2001). Com base nos mesmos dados e usando modelo de regressão multinível, Barbosa e Fernandes (2001) verificaram que, depois do controle do nível socioeconômico do aluno, variáveis referentes à infra-estrutura e aos equipamentos escolares são preditoras de um bom desempenho dos alunos. Os mesmos autores assinalam que, quando se objetiva pesquisar sobre o desempenho escolar, o nível socioeconômico familiar e o conhecimento prévio do aluno devem ser primeiramente considerados.

Em um estudo realizado por Fukuda (2003) foram observadas as características de professores do Distrito Federal/ Brasil que impactavam no desempenho de alunos em Língua Portuguesa. Foi verificado que tanto variáveis relacionadas ao aluno quanto variáveis relacionadas à turma influenciaram o desempenho do aluno. No entanto, as primeiras parecem ter maior impacto.

Jesus (2004) identificou as variáveis preditoras do desempenho acadêmico de alunos da $8^{\mathrm{a}}$ série do Ensino Fundamental em Língua Portuguesa avaliados no SAEB de 2001. A partir de análises de regressão multinível foi verificado que o nível socioeconômico da escola e a escolaridade dos pais foram as variáveis de controle mais relacionadas ao desempenho acadêmico. A autora também observou que quatro variáveis do nível do aluno afetavam o desempenho escolar. São elas: atraso escolar, aluno trabalha, apoio dos pais e aluno faz dever de casa. Considerando o nível da escola, verificou-se que as escolas que mais agregavam valor ao desempenho dos alunos possuíam as seguintes características: 1) recursos tecno-pedagógicos adequados; 2) professores que passam e corrigem a lição de casa; 3 ) instalações físicas em bom estado de conservação; 4) professores comprometidos com a aprendizagem dos alunos; 5) professores que têm altas expectativas em relação ao desempenho dos alunos, 6) alunos cujos pais apóiam, incentivam e conversam com eles sobre assuntos diversos e 7) alunos que não trabalham.

Pesquisas em outras culturas apresentam resultados similares. Em um estudo longitudinal com uma amostra de jovens norte-americanos investigou-se a relação entre fatores individuais e fatores da escola com os escores de um teste de Ciências. Análises hierárquicas mostraram que sucesso prévio teve uma influência efetiva sobre realizações subseqüentes no escore do teste (Young, Reynolds \& Walberg, 1996). Em um estudo realizado por Willms e Somers (2000), com amostras de 13 países da América Latina, verificou-se a relação de resultados escolares com relações familiares, práticas e políticas escolares. Foi constatado que as relações entre desempenho escolar e base familiar variavam entre os países. No entanto, em todos os países, as escolas mais efetivas apresentaram as seguintes características: recursos escolares satisfatórios, salas de aula onde os alunos não são agrupados por habilidade e não apresentam níveis de conhecimento muito diferenciados, alunos que são testados freqüentemente, escolas com alto grau de envolvimento parental e salas de aula com clima positivo, ou seja, em que há respeito e disciplina.

Diante da necessidade de seguir um marco teórico (Ferrão, 2003) e frente aos modelos aqui apresentados, no presente artigo optou-se pelo modelo apresentado por Jesus (2004). A razão disso é que a referida autora, além de utilizar análise de regressão multinível, delineou seu modelo a partir de resultados do SAEB de 2001, especificamente os referentes aos alunos da $8^{\text {a }}$ série do Ensino Fundamental avaliados em Língua Portuguesa. Vale ressaltar que o interesse aqui recai sobre os resultados dos alunos da $3^{\mathrm{a}}$ série do Ensino Médio, avaliados tanto em Língua Portuguesa quanto em Matemática, no SAEB de 2001.

\section{Método}

\section{Participantes}

No SAEB de 2001 participaram 6.935 escolas, 6.820 diretores, 21.754 docentes e 287.719 alunos distribuídos nas três séries avaliadas (INEP, 2001a). A amostra considerada no presente estudo foi referente aos alunos da $3^{\mathrm{a}}$ série do Ensino Médio, a saber: 36.263 alunos avaliados em Língua Portuguesa e 36.158 alunos avaliados em Matemática. Para a realização da análise multinível foram agrupados os bancos de dados de alunos, professores, diretores e escolas. Para isso foram considerados apenas os questionários de professores, diretores e escolas em que pelo menos um aluno respondeu ao teste. Dessa forma, a amostra ficou composta por 72.379 alunos, 4.834 professores, 1.842 diretores e 1.842 escolas. Ressalta-se que a maior parte dos avaliados foi do sexo feminino (57,7\%), com idades entre 16 e 17 anos (44,5\%), auto-declarada da etnia/cor branca $(48,8 \%)$, oriunda da região Nordeste $(42,5 \%)$ e formada por estudantes da rede pública de ensino (56\%).

\section{Instrumentos}

Além do desempenho dos estudantes nos testes de Língua Portuguesa e Matemática, considerados medidas cognitivas que visam captar o que os alunos aprenderam, no SAEB são também aplicadas medidas contextuais que visam captar a origem social dos alunos e as condições em que eles estudam. A seguir são descritos os questionários aplicados.

1) Questionário de Alunos. Os alunos responderam dois questionários socioculturais. O primeiro era composto por 
43 questões referentes à caracterização sócio-demográfica como, por exemplo, sexo, etnia, estrutura familiar. O segundo questionário do aluno era composto por dois tipos, um para o aluno avaliado em Língua Portuguesa e outro para o aluno avaliado em Matemática.

2) Questionário de Professores. Os professores responderam um questionário composto por 98 questões sobre formação profissional, práticas pedagógicas, nível socioeconômico-cultural, entre outras.

3) Questionários de Diretores. Composto por 72 questões que abordavam os seguintes conteúdos: caracterização sóciodemográfica, formação profissional, nível socioeconômico e cultural, estilos de liderança e formas de gestão.

4) Questionário da Escola. Respondido por um funcionário da secretaria de educação, é composto por oito questões. Nele são avaliadas as condições físicas da escola, segurança, conservação e biblioteca (INEP, 2001a).

\section{Análise de dados}

Inicialmente procedeu-se à redução do número de variáveis contidas nos questionários contextuais. Foi utilizado o software SPSS 14.0 para a realização da análise dos componentes principais. Atentando para a recomendação de Johnson e Wichern (1998), todas as variáveis foram padronizadas antes da análise dos componentes principais, por apresentarem diferentes escalas e variância. Após a redução das variáveis contidas nos questionários contextuais foram iniciadas as análises de regressão multinível. Utilizou-se o programa $M L w i N$ na sua versão 2.0, desenvolvido por Goldstein e cols. (1998).

\section{Resultados}

Foram realizadas análises dos componentes principais com o objetivo de reduzir o número de variáveis dos questionários contextuais. Das 210 variáveis analisadas, obtiveram-se 12 componentes que foram utilizados na análise de regressão multinível. Os componentes identificados com seus respectivos coeficientes de fidedignidade (alfa de Cronbach) foram: Nivel socioeconômico do aluno $(0,87)$, Relação da família com o aluno (0,77), Relação da família do aluno com a escola $(0,72)$, Recursos culturais $(0,75)$, Experiência profissional do professor $(0,88)$, Liderança do diretor $(0,92)$, Condições de trabalho do diretor e da equipe $(0,83)$, Trabalho colaborativo $(0,82)$, Clima acadêmico $(0,88)$, Clima disciplinar $(0,81)$, Recursos pedagógicos $(0,82)$ e Situações das instalações e equipamentos da escola $(0,91)$. Os construtos teóricos previamente definidos pelos construtores dos questionários do SAEB e não identificados a partir das análises de componentes principais foram: Motivação e Auto-estima, Trajetória escolar dos alunos e Condições de trabalho do professor. Apenas duas variáveis dos questionários contextuais não agrupadas por meio da análise dos componentes principais foram consideradas separadamente na análise multinível, a saber: "Você gosta de estudar Língua Portuguesa/Matemática?" e "Em Língua Portuguesa/Matemática, como você se compara em relação aos seus colegas de turma?".

Para a realização da análise de regressão multinível, considerou-se o desempenho dos alunos em Matemática como variável dependente. Por meio da inserção da variável dicotômica (dummy) disciplina ( 0 = Matemática e 1 = Língua Portuguesa) foi possível observar a diferença do desempenho médio dos alunos avaliados em Língua Portuguesa em relação àqueles avaliados em Matemática, bem como a contribuição das variáveis explicativas no que se refere ao desempenho escolar em Língua Portuguesa. Esse procedimento de inserção de varáveis dummies (uma para cada disciplina avaliada) foi utilizado anteriormente por Albernaz, Ferreira e Franco (2002) na estimativa de uma função de produção educacional para o Ensino Fundamental brasileiro com base nos dados do SAEB de 1999. Os autores inseriram variáveis dummies com a finalidade de se considerar o maior número possí-

Tabela 1. Estatísticas descritivas das variáveis consideradas na análise de regressão multinível.

\begin{tabular}{lcccc}
\hline Variável & Média & Desvio-padrão & Valor mínimo & Valor máximo \\
\hline Desempenho escolar em Matemática & 277,75 & 52,18 & 175,88 & 117,44 \\
Desempenho escolar em L. Portuguesa & 262,93 & 50,75 & 0,20 & 440,52 \\
Nível socioeconômico do aluno & 1,36 & 0,45 & 1,00 & 516,93 \\
Relação da família com o aluno & 2,72 & 0,58 & 1,00 & 5,00 \\
Relação da família com a escola & 2,68 & 0,73 & 0,00 & 4,00 \\
Recursos culturais do aluno & 1,49 & 0,25 & 0,29 & 4,00 \\
Condições de trabalho do diretor e equipe & 2,08 & 0,43 & 1,00 & 3,00 \\
Experiência profissional do professor & 3,27 & 0,82 & 1,67 & 3,50 \\
Trabalho colaborativo & 3,34 & 0,37 & 1,90 & 5,00 \\
Clima acadêmico & 3,70 & 0,55 & 1,33 & 4,33 \\
Clima disciplinar & 2,44 & 0,35 & 1,00 & 5,00 \\
Recursos pedagógicos & 3,55 & 1,47 & 1,22 & 3,00 \\
Situação dos equipamentos & 2,63 & 0,34 & 3,00 & 27,00 \\
Atraso escolar & 1,42 & 1,76 & 1,00 & 4,33 \\
Comparação do aluno com os colegas & 2,00 & 0,54 & 1,00 & $-5,00$ \\
Aluno gosta da disciplina & 1,66 & 0,47 & 1,00 \\
Aluno faz dever de casa & 3,46 & 1,27 & 1,00 \\
Aluno trabalha & 1,70 & 0,92 & & 2,00 \\
\hline
\end{tabular}


Fatores Associados ao Desempenho Escolar

Tabela 2. Estimativas para o modelo nulo.

\begin{tabular}{|c|c|c|c|}
\hline Parâmetro fixo & Coeficiente $\left(\beta_{o j}\right)$ & Erro-padrão (e.p.) & Razão $t$ \\
\hline $\begin{array}{l}\left(\gamma_{00}\right) \text { Intercepto - Média das } \\
\text { escolas em Matemática }\end{array}$ & 277,12 & & \\
\hline $\begin{array}{l}\left(\gamma_{10}\right) \text { Disciplina - Média das } \\
\text { escolas em L. Portuguesa }\end{array}$ & $-14,22$ & 1,18 & $-12,01 *$ \\
\hline Parâmetro Aleatório & Variância & e.p. & Razão $t$ \\
\hline$\left(\sigma_{\mathrm{u} 0}^{2}\right)$ Variância do nível 2 & 1.187 & 29,97 & $39,61^{*}$ \\
\hline$\left(\sigma_{\mathrm{e}}^{2}\right)$ Variância do nível 1 & 1.379 & 7,44 & $185,35^{*}$ \\
\hline Deviance (-2log verossimilhança) & 738.680 & & \\
\hline
\end{tabular}

Nota: $* p<0,001$.

vel de alunos por escola, a fim de tornar as estimativas mais confiáveis. Ressalta-se que no presente estudo esse procedimento também é justificável na medida em que o desempenho dos alunos em Língua Portuguesa apresenta uma correlação alta e significativa com o desempenho em Matemática. Ainda, a variável referente ao desempenho escolar dos alunos foi transformada para a escala de proficiência do SAEB que varia de 0 a 500. Também, todas as variáveis explicativas foram padronizadas com média zero e desvio padrão igual a 1 . Isso foi realizado porque as variáveis foram medidas em escalas diferenciadas e, dessa forma, seria difícil interpretar os resultados (Ferrão, 2003; Hox, 2002).

Na Tabela 1 são apresentadas as estatísticas descritivas das variáveis contínuas consideradas na análise de regressão multinível. Foram utilizados pesos normalizados padronizados e as variáveis são apresentadas na escala original de medição.

Dessa forma, deu-se início a modelagem multinível. Inicialmente adicionou-se apenas uma constante sem variáveis explicativas e foi estimado o modelo nulo que serve como base para comparação com os modelos subseqüentes. Nesse modelo, o desempenho escolar do aluno $i$ que estuda na escola $j$ é definido pelo intercepto $\left(\beta_{o j}\right)$ e pelos termos de erro $\left(e_{i j}\right)$. $O$ termo $\beta_{o j}$ é especificado aditivamente pelos termos: $\gamma_{00}$, que representa a média global de desempenho, e $u_{\mathrm{o}}$, que representa o afastamento de desempenho escolar da escola $j$ à média global $\gamma_{00}$. Admite-se que os efeitos aleatórios associados aos níveis 1 e 2 seguem distribuição normal com média 0 e variância $\sigma_{\mathrm{e}}^{2}$ e $\sigma_{\mathrm{u} 0}^{2}$, respectivamente, e são independentes (Ferrão, 2003; Hox, 2002). Os resultados são apresentados na Tabela 2.

Como pode ser observado, a estimativa da média global de desempenho escolar $\left(\gamma_{00}\right)$ em Matemática é de 277,12, enquanto a estimativa da variância entre escolas $\left(\sigma^{2}{ }_{u 0}\right)$ é de 1.187 (com e.p. de 29,97) e a estimativa da variância intra-escola é de 1.379 (com e.p. de 7,44). Para a disciplina de Língua Portuguesa há um decréscimo de -14,22 (com e.p. de 1,18$)$ pontos da média em relação à disciplina de Matemática, o que equivale a 262,9 pontos.

A partir das informações referentes à variância dos níveis 1 e 2, calculou-se o coeficiente de correlação intraescola (i.c.c.). O i.c.c. pode variar de 0 a 1 . Quando seu valor é nulo ou se aproxima de zero, isso significa que as escolas são homogêneas entre si e que o desempenho escolar do aluno é independente da escola que freqüenta (Ferrão, 2003). O resultado encontrado sugere que $46 \%$ da variância do desempenho escolar dos alunos deve-se à variabilidade entre as escolas, o que torna necessário o uso de modelos de regressão multinível. Ainda, a estimativa do deviance $(-2 \log$ verossimilhança) para o modelo nulo foi igual a 738.680. O deviance reflete a falta de ajuste entre os dados e o modelo. Como regra para sua interpretação, deve-se comparar a magnitude das diferenças entre o seu valor e aquele encontrado no modelo seguinte (Snijders \& Bosker, 1999). Se a diferença dos deviances for significativa, o modelo com o menor deviance é considerado melhor (Kreft \& De Leeuw, 1998). Nesse estudo, utilizou-se como critério de escolha entre dois modelos a diferença entre os deviances, bem como a quantidade de variância explicada.

Após a estimação do modelo nulo, foram incluídas as variáveis relacionadas à composição e seletividade escolar como variáveis de controle (Modelo 2). A razão disso é que se procura verificar as características de alunos e escolas que favorecem o desempenho escolar, após o controle completo ou parcial do efeito do nível socioeconômico e de características idiossincráticas dos alunos. A intenção é de observar quais são as outras fontes de variação entre as escolas, além das características de seletividade e composição escolar que são passíveis de intervenção. Fica evidente que os alunos não são designados para freqüentar as escolas de maneira aleatória, e sim, suas condições socioeconômicas e culturais é que vão determinar a escolha por uma escola ou outra (Fletcher, 1998). As variáveis consideradas foram: nível socioeconômico, sexo e etnia do aluno, tanto no nível da escola quanto no nível do aluno, para controlar o efeito dessas variáveis em ambos os níveis. Ressalta-se que foi dado um tratamento específico à variável etnia/raça do aluno. Nos questionários do aluno do SAEB, a pergunta sobre a etnia/raça do aluno é feita da seguinte maneira: "Como você se considera? (1) Branco(a), (2) Pardo(a)/Mulato(a), (3) Negro(a), (4) Amarelo(a) e (5) Indígena. Por meio de um teste de comparação de médias Anova Oneway, com teste Post Hoc de Scheffe e utilizando pesos normalizados, verificou-se que as médias dessas categorias diferiam em relação ao desempenho médio escolar 
$(F=628,25$, g.l. $=71,754, p<0,001)$. Todavia, foi verificado que a média de desempenho escolar do grupo de alunos pardo(a)/amarelo(a) (média=253,13, d.p.=43,23) não difere estatística e significativamente $(p>0,05)$ do grupo de alunos indígena (média $=250,02, d . p .=42,83$ ). Também não foi verificada diferença entre as médias de desempenho escolar do grupo de alunos negros (média $=244,74$, d.p. $=40,50$ ) em relação ao grupo de alunos indígenas, considerando um nível de significância $p<0,001$. O grupo de alunos amarelos difere estatística e significativamente em relação aos demais (média $=261,23$, d.p. $=46,13$ ), no entanto, como se trata de um grupo pequeno $(5,7 \%$ dos alunos), não foi possível considerá-lo como uma categoria específica na análise de regressão multinível. Dessa forma, a variável etnia foi considerada com duas categorias, a saber, alunos brancos (média $=269,11, d . p .=48,17)$ e alunos não-brancos (média $=252,88, d . p .=43,43$ ).

Na modelagem multinível verificou-se que as variáveis de controle explicaram $76 \%$ da variância do nível da escola. Dito de outra maneira, $76 \%$ da variância observada entre as escolas no desempenho escolar médio dos seus alunos deve-se à seletividade e à composição escolar. Em relação ao nível 1, verificou-se que a explicação era bem mais modesta, apenas $1 \%$. Depois deste controle, a correlação intra-escola diminuiu para 0,17 . Isso significa que depois de controlar os efeitos da seletividade e composição escolar, $17 \%$ da variância pode ser atribuída ao nível da escola.

Seguindo os passos propostos por Hox (2002) foram incluídas as demais variáveis do nível do aluno (Modelo 3). Verificou-se que os coeficientes de regressão de sete variáveis incluídas no modelo foram estatisticamente significativos (razão $t>2$ ). A variável que mais afetou o desempenho escolar dos alunos foi Atraso escolar. A cada aumento de uma unidade na escala de escore padrão de atraso escolar, o desempenho médio dos alunos diminuiu em 10,67 pontos (com e.p. de 0,17). Outra variável que explicou a variância do desempenho, só que positivamente, foi Comparação do aluno com os colegas. As demais variáveis que entraram no modelo foram: Recursos culturais de que o aluno dispõe em casa $(3,80)$, Relação da família com a escola $(-4,98)$, Aluno gosta de estudar a disciplina $(4,75)$, Aluno faz dever de casa $(2,54) \mathrm{e}$, por fim, Aluno trabalha $(-1,63)$. Verificou-se uma explicação de $14 \%$ da variância do desempenho escolar em relação ao nível 1 ; já em relação ao nível 2 foi verificada uma explicação de $81 \%$ da variância do desempenho escolar. Como as variáveis de seletividade e composição escolar foram responsáveis por $76 \%$ da explicação do desempenho escolar no nível da escola e $1 \%$ no nível do aluno, verifica-se, assim, que as variáveis do nível do aluno explicaram 5\% da variância do nível da escola e $13 \%$ no nível do aluno.

Em seguida, foram incluídas no modelo as variáveis explicativas referentes ao nível da escola (Modelo 4). Algumas dessas variáveis foram mensuradas no nível do aluno e agregadas para o nível da escola, a saber: Recursos culturais, Atraso escolar, Relação da família do aluno com a escola, Aluno faz dever de casa, Aluno trabalha e Aluno gosta de estudar a disciplina. As variáveis originalmente mensuradas no nível da escola e consideradas nesse mesmo nível foram: Clima disciplinar da escola, Trabalho colaborativo entre a equipe escolar, Situação dos equipamentos e das instalações da escola e, por fim, Experiência profissional do professor. As variáveis que não contribuíram significativamente para a explicação da variável desempenho escolar foram excluídas do modelo.

As variáveis incluídas no modelo que mais afetaram no desempenho escolar dos estudantes foram Recursos culturais e Atraso escolar, ambas agregadas para a escola. Todavia, deve-se observar que a primeira teve um efeito positivo na explicação, enquanto a segunda teve efeito negativo. As outras variáveis consideradas que contribuíram para a explicação em sentido positivo foram: Clima disciplinar da escola (2,04), Aluno faz dever de casa agregado $(1,76)$, Situação dos equipamentos e instalações da escola $(1,42)$, Trabalho colaborativo entre a equipe escolar $(2,19)$, Experiência do professor $(1,59)$ e Aluno gosta da disciplina agregado $(0,96)$. Em sentido negativo, também se verificou efeitos das seguintes variáveis, ambas agregadas: Aluno trabalha $(-3,22)$ e Relação da família do aluno com a escola $(-2,81)$. Observa-se que houve uma explicação de $85 \%$ da variância do desempenho escolar em relação ao nível 2. Como já haviam sido explicados $81 \%$ da variância do desempenho escolar, verificou-se que as variáveis do nível da escola incluídas no modelo explicaram $4 \%$ da variabilidade no desempenho escolar médio das escolas. Não foi verificado acréscimo na explicação do desempenho escolar em relação ao nível 1 .

No último modelo testado (Modelo 5) verificou-se o efeito randômico dos coeficientes de inclinação das variáveis do nível do aluno que já haviam entrado no modelo. Em outras palavras, procurou-se verificar se essas variáveis se comportam diferentemente entre as escolas. As variáveis que não apresentaram coeficiente de regressão com efeito randômico foram estimadas novamente com os coeficientes de regressão fixos. Os resultados da modelagem são apresentados na Tabela 3.

$\mathrm{O}$ ajuste deste modelo em comparação ao modelo anterior ficou significativo $\left(\mathrm{D}_{4}-\mathrm{D}_{5} / g l=26,18\right)$ e, assim, esse último modelo foi considerado o mais adequado. As variáveis que apresentaram efeito randômico e que, portanto, comportamse diferentemente entre as escolas foram: Nível socioeconômico do aluno (-1,71), Sexo masculino $(5,92)$, Atraso escolar $(-10,57)$, Comparação do aluno com os colegas $(5,81)$, Aluno gosta de estudar a disciplina $(4,41)$, Aluno faz dever de casa $(2,37)$ e Aluno trabalha $(-1,57)$. Apenas as variáveis referentes à Etnia do aluno, Relação da família com a escola e Recursos culturais não tiveram efeitos diferenciados sobre o desempenho escolar entre as escolas. Ressalta-se que o coeficiente de regressão negativo do nível socioeconômico do aluno é decorrente do fato da variável nível socioeconômico agregada ter entrado primeiramente no modelo e ter explicado grande parte da variância relacionada ao nível socioeconômico. Como já assinalado, esta variável representa a média aritmética do nível socioeconômico dos alunos que estudam na escola. Foi também testado um modelo considerando apenas o nível socioeconômico do aluno e seu efeito foi positivo e de magnitude muito maior. Esse resultado corrobora a pesquisa de Albernaz e cols. (2002) que indica que quanto mais "rica" a escola, menor o efeito das condições familiares de cada aluno. 
O último passo a ser considerado seria verificar efeitos de interação entre os níveis (cross-level) (Hox, 2002). Frente à complexidade do modelo já elaborado, optou-se por não testar efeitos de interação entre os níveis. Como assinala Hox (2002), os efeitos da interação são de difícil compreensão e os pesquisadores devem tratar deles com cuidado.

Tabela 3. Comparação entre o Modelo 4 e o Modelo 5.

\begin{tabular}{|c|c|c|c|c|c|c|c|}
\hline \multicolumn{2}{|c|}{ Variáveis explicativas } & \multicolumn{3}{|c|}{ Modelo 4 - Inclusão das variáveis do nível 2} & \multicolumn{3}{|c|}{$\begin{array}{l}\text { Modelo } 5 \text { - Inclusão do efeito randômi- } \\
\text { co nas variáveis do nível } 1\end{array}$} \\
\hline \multicolumn{2}{|r|}{ Parâmetro Fixo } & Efeito** & $\begin{array}{l}\text { Erro-padrão } \\
\text { (e.p.) }\end{array}$ & Razão t & Efeito $^{* *}$ & e.p. & Razão t \\
\hline$\left(\gamma_{00}\right)$ & Intercepto & 281,56 & 1,54 & -- & 279,31 & 1,44 & -- \\
\hline$\left(\gamma_{10}\right)$ & Disciplina L. Portuguesa & $-18,14$ & 0,63 & $-28,79 *$ & $-14,14$ & 0,51 & $-27,72 *$ \\
\hline$\left(\gamma_{01}\right)$ & NSE*** agregado & 10,49 & 0,93 & $11,28 *$ & 11,62 & 0,90 & $12,91^{*}$ \\
\hline$\left(\gamma_{20}\right)$ & $\mathrm{NSE}^{* * *}$ & $-1,88$ & 0,23 & $8,17^{*}$ & $-1,71$ & 0,24 & $-7,12 *$ \\
\hline$\left(\gamma_{30}\right)$ & Sexo masculino & 5,95 & 0,28 & $21,25 *$ & 5,92 & 0,32 & $18,50 *$ \\
\hline$\left(\gamma_{03}\right)$ & Etnia aluno não branco agregado & -- & -- & -- & $-2,39$ & 0,81 & $-2,95^{*}$ \\
\hline$\left(\gamma_{40}\right)$ & Etnia aluno não branco & $-2,21$ & 0,86 & $-2,57^{*}$ & $-1,36$ & 0,29 & $-4,69 *$ \\
\hline$\left(\gamma_{50}\right)$ & Atraso escolar & $-10,26$ & 0,18 & $-57,00 *$ & $-10,57$ & 0,19 & $-55,63^{*}$ \\
\hline$\left(\gamma_{60}\right)$ & Comparação do aluno com os colegas & 6,13 & 0,14 & $43,79 *$ & 5,81 & 0,16 & $36,31^{*}$ \\
\hline$\left(\gamma_{70}\right)$ & Recursos culturais do aluno & 3,58 & 0,21 & $17,05 *$ & 3,59 & 0,20 & $17,95, *$ \\
\hline$\left(\gamma_{80}\right)$ & Relação da família com a escola & $-4,86$ & 0,14 & $-34,71 *$ & $-4,76$ & 0,14 & $-34,00 *$ \\
\hline$\left(\gamma_{90}\right)$ & Aluno gosta da disciplina & 4,69 & 0,14 & $33,50 *$ & 4,41 & 0,15 & $29,40 *$ \\
\hline$\left(\gamma_{100}\right)$ & Aluno faz dever de casa & 2,41 & 0,14 & $17,21 *$ & 2,37 & 0,16 & $14,81^{*}$ \\
\hline$\left(\gamma_{110}\right)$ & Aluno trabalha & $-1,32$ & 0,16 & $-8,25^{*}$ & $-1,57$ & 0,16 & $-9,81^{*}$ \\
\hline$\left(\gamma_{04}\right)$ & Recursos culturais agregado & 5,28 & 0,81 & $6,52 *$ & 4,27 & 0,77 & $5,54 *$ \\
\hline$\left(\gamma_{05}\right)$ & Atraso escolar agregado & $-4,46$ & 0,50 & $-8,92^{*}$ & $-3,66$ & 0,46 & $-7,96^{*}$ \\
\hline$\left(\gamma_{06}\right)$ & Aluno trabalha agregada & $-3,22$ & 0,39 & $-8,26^{*}$ & $-2,39$ & 0,35 & $-6,83^{*}$ \\
\hline$\left(\gamma_{07}\right)$ & Clima disciplinar da escola & 2,04 & 0,34 & $6,00 *$ & 1,88 & 0,31 & $6,06^{*}$ \\
\hline$\left(\gamma_{08}\right)$ & Relação família/escola agregada & $-2,81$ & 0,28 & $-10,04 *$ & $-2,41$ & 0,27 & $-8,93^{*}$ \\
\hline$\left(\gamma_{09}\right)$ & Dever de casa agregada & 1,76 & 0,28 & $6,29 *$ & 1,81 & 0,27 & $6,70 *$ \\
\hline$\left(\gamma_{010}\right)$ & Situaç. dos equipam. e instalações & 1,42 & 0,33 & $4,30^{*}$ & 1,41 & 0,29 & 4,86 \\
\hline$\left(\gamma_{011}\right)$ & Trabalho colaborativo & 2,19 & 0,45 & $4,87 *$ & 1,39 & 0,42 & $3,31 *$ \\
\hline$\left(\gamma_{012}\right)$ & Experiência do professor & 1,59 & 0,28 & $5,67 *$ & 1,08 & 0,26 & $4,15^{*}$ \\
\hline \multirow[t]{2}{*}{$\left(\gamma_{013}\right)$} & gosta da disciplina agregado & 0,96 & 0,31 & $3,10^{*}$ & -- & -- & -- \\
\hline & Parâmetro Aleatório - Nível 2 & $\sigma^{2}{ }_{u 0}$ & e.p. $\left(\sigma^{2}{ }_{u 0}\right)$ & Razão t & $\sigma_{u 0}^{2}$ & e.p. $\left(\sigma_{u 0}^{2}\right)$ & Razão t \\
\hline$\left(\sigma_{\mathrm{u} 0}^{2}\right)$ & Variância - intercepto & 179 & 5,92 & $30,24^{*}$ & 151 & 6,64 & $22,74^{*}$ \\
\hline$\left(\sigma_{\mathrm{u} 1}^{2}\right)$ & Var. inclinação NSE & & & & 11 & 2,74 & $4,01^{*}$ \\
\hline$\left(\sigma_{\mathrm{u} 2}^{2}\right)$ & Var. inclinação sexo masculino & & & & 77 & 7,99 & $9,63^{*}$ \\
\hline$\left(\sigma_{\mathrm{u} 3}^{2}\right)$ & Var. inclinação atraso escolar & & & & 15 & 2,35 & $6,38^{*}$ \\
\hline$\left(\sigma^{2}{ }_{u 4}\right)$ & Var. inclinação comparação & & & & 17 & 1,94 & $8,76^{*}$ \\
\hline$\left(\sigma^{2}{ }_{\mathrm{u} 5}\right)$ & Var. inclinação gosta disciplina & & & & 5 & 1,62 & $3,09^{*}$ \\
\hline$\left(\sigma_{\mathrm{u} 6}^{2}\right)$ & Var. inclinação dever de casa & & & & 9 & 1,66 & $5,42 *$ \\
\hline \multirow[t]{2}{*}{$\left(\sigma_{\mathrm{u} 7}^{2}\right)$} & Var. inclinação aluno trabalha & & & & 5 & 1,59 & $3,14^{*}$ \\
\hline & Parâmetro Aleatório - Nível 1 & $\sigma_{\mathrm{e}}^{2}$ & e.p. $\left(\sigma_{\mathrm{e}}^{2}\right)$ & Razão t & $\sigma_{\mathrm{e}}^{2}$ & e.p. $\left(\sigma_{\mathrm{e}}^{2}\right)$ & Razão t \\
\hline$\left(\sigma_{\mathrm{e}}^{2}\right)$ & Variância de $\left(\mathrm{R}_{\mathrm{ij}}\right)$ & 1.186 & 6,46 & $183,59 *$ & 1.119 & 6,82 & $164,08 *$ \\
\hline \multicolumn{2}{|l|}{ Deviance } & 707.378 & & & 706.488 & & \\
\hline \multicolumn{2}{|c|}{ Número de parâmetros } & 26 & & & 60 & & \\
\hline \multicolumn{2}{|c|}{ Diferença do Deviance $\left(D_{4}-D_{5}\right)$} & 890 & & & & & \\
\hline \multicolumn{2}{|c|}{ Diferença de Parâmetros (g.l.) } & 34 & & & & & \\
\hline \multicolumn{2}{|c|}{ Teste de $\chi^{2}$} & 26,18 & & & & & \\
\hline
\end{tabular}

Nota: $* p<0,001 ; * *$ Coeficiente de regressão $(\beta)$; *** Nível socioeconômico do aluno. 


\section{Discussão e Conclusão}

O presente estudo teve como objetivo construir um modelo multinível de desempenho escolar, identificando quais variáveis explicativas afetam o desempenho dos estudantes da $3^{a}$ série do Ensino Médio nas disciplinas de Língua Portuguesa e Matemática. Foram seguidos os passos propostos por Hox (2002). Verificou-se que as variáveis de controle e seletividade escolar explicaram $76 \%$ da variância do desempenho escolar entre as escolas, restando apenas $24 \%$ a serem explicados por práticas dos alunos e das escolas. Esse resultado foi similar ao encontrado por Jesus (2004), que verificou que 79\% da variância do desempenho escolar eram devidos às variáveis de controle. Dessas, a maior contribuição foi da variável Nível socioeconômico da escola. Para cada aumento de um desvio-padrão do Nível socioeconômico da escola, há um aumento do desempenho escolar do aluno em 11,62 pontos na escala de proficiência do SAEB que varia de 0 a 500. Verificou-se também que o nível socioeconômico do aluno parece ter seu efeito bastante reduzido $(-1,71)$, após a inclusão do nível socioeconômico da escola. A partir desse resultado, levanta-se a hipótese de que tanto alunos com baixo nível socioeconômico quanto alunos de alto nível socioeconômico, quando estudam em escolas de nível socioeconômico elevado, tendem a obter melhores desempenhos escolares do que aqueles que estudam em escolas que possuem poucos recursos. Todavia, essa hipótese precisa ser testada em pesquisas futuras. Como assinalam Soares e Alves (2003), é um constrangimento real o fato de o nível socioeconômico poder ajudar ou dificultar tão diretamente no aprendizado do aluno. É evidente que estudantes que vivem uma situação de desvantagem social têm piores condições de habitação, saúde e alimentação. Esses são efeitos cumulativos que podem torná-los mais fracos física e emocionalmente, o que dificulta a aprendizagem (Ferrão, 2003).

Estudantes do sexo masculino também atingem em média 5,92 pontos a mais na escala de proficiência do SAEB do que estudantes do sexo feminino, no entanto, verificou-se que esse efeito varia de escola para escola (efeito randômico). A variável do sexo do aluno agregada para o nível da escola foi desconsiderada do modelo final por não contribuir significativamente para a explicação do desempenho escolar, embora tivesse sido significativa no Modelo 1. Ainda, alunos não-brancos (negros, indígenas, amarelos e pardos) pontuam em média -1,36 pontos na escala do SAEB em relação aos alunos brancos. Quando a variável foi agregada para o nível da escola, verificou-se uma contribuição de -2,39.

Em relação às demais variáveis consideradas no nível do aluno, verificou-se que a variável que mais afeta o desempenho escolar é o Atraso escolar. A cada aumento de um desvio-padrão do Atraso escolar o desempenho médio dos alunos diminui em 10,58 pontos. Como pôde ser observado na Tabela 1 , o desvio-padrão dessa variável na escala original foi igual a 1,8 . Isto quer dizer que o aumento de 1,8 anos na média do atraso escolar dos alunos resulta na diminuição de 10,58 pontos na escala de proficiência do SAEB. Ressalta-se que esse impacto é diferenciado de escola para escola.

As outras variáveis do nível do aluno que afetam o desempenho escolar em sentido positivo foram: Comparação do aluno com os colegas, com efeito diferenciado de escola para escola; Recursos culturais de que o aluno dispõe em casa, como acesso a computadores com Internet, livros, revistas de informação geral, jornais etc.; Aluno gosta de estudar a disciplina, com efeito diferenciado de escola para escola e aluno faz dever de casa. Por outro lado, as variáveis do nível do aluno que afetam o desempenho escolar em sentido negativo foram: Relação da família do aluno com a escola e Aluno trabalha. Nessa última variável houve variação de escola para escola.

Chama a atenção o fato da variável Relação da família do aluno com a escola ter um efeito negativo no desempenho escolar dos alunos. Duas hipóteses são formuladas a esse respeito. Primeira, os itens que avaliam esse componente no questionário do SAEB podem não ser adequados e estariam realmente avaliando a exigência ou cobrança dos pais para com os filhos. A segunda hipótese é a de que, possivelmente, são os pais dos alunos com maiores problemas de aprendizagem que recorrem às escolas com maior freqüência. Esse aspecto precisa ser melhor pesquisado em estudos futuros.

Como pôde ser observado houve uma modelagem de $13 \%$ da variância do desempenho escolar em relação ao nível 1. Conforme assinala Fletcher (1998), é relativamente difícil explicar a variância do nível 1 na educação, o que sugere que a contribuição do presente estudo foi bastante significativa. Por exemplo, Jesus (2004), utilizando a mesma metodologia, explicou $6 \%$ da variância da variável de desempenho escolar.

As variáveis do nível da escola que mais afetaram o desempenho escolar foram Recursos culturais e Atraso escolar, ambas agregadas para o nível da escola. Todavia, deve-se observar que a primeira teve um efeito positivo na modelagem, enquanto a segunda teve efeito negativo. As outras variáveis consideradas que contribuíram para a explicação do desempenho escolar em sentido positivo foram: Clima disciplinar da escola, Aluno faz dever de casa agregado, Situação dos equipamentos e instalações da escola, Trabalho colaborativo da equipe escolar e Experiência do professor. Em sentido negativo, também se verificou efeito da variável Aluno trabalha agregado. Por fim, a variável Aluno gosta da disciplina (agregada para a escola) foi retirada do modelo final por não apresentar contribuição significativa, embora, previamente, tivesse sido considerada no Modelo 4. Verificou-se que as variáveis do nível da escola incluídas no modelo explicaram $4 \%$ da variabilidade no desempenho escolar médio das escolas.

Como recomendação, sugere-se que os questionários contextuais do SAEB sejam revisados. Os construtos psicológicos Motivação e Auto-estima, embora propostos pelos construtores dos questionários, não foram identificados. A inserção desses construtos psicológicos na modelagem multinível poderia favorecer ainda mais a compreensão dos determinantes do desempenho escolar.

Diante dos resultados encontrados conclui-se que os objetivos da presente pesquisa foram alcançados. Objetivou-se construir um modelo de desempenho escolar que favorecesse a compreensão dos fatores que determinam o bom desempenho dos estudantes, bem como o processo de formação das desigualdades educacionais. Compartilha-se a concepção do INEP de que os dados e resultados obtidos 
por meio do SAEB ajudarão o Ministério da Educação e Desporto e as Secretarias Estaduais e Municipais de Educação a direcionarem seu apoio técnico e financeiro, visando o melhoramento da educação brasileira. Espera-se que o presente estudo atinja esse fim.

\section{Referências}

Albernaz, A., Ferreira, F. H. \& Franco, C. (2002). Qualidade e eqüidade da educação fundamental brasileira. Rio de Janeiro: PUC-Rio.

Barbosa, M. E. F. \& Fernandes, C. (2001). A escola brasileira faz diferença? Uma investigação dos efeitos da escola na proficiência em matemática dos alunos da $4^{\mathrm{a}}$ série. Em C. Franco (Org.), Avaliação, ciclos e promoção na educação (pp. 155-172). Porto Alegre: Artmed.

Ferrão, M. E. (2003). Introdução aos modelos de regressão multinível em educação. Campinas: Editora Komedi.

Fletcher, P. R. (1998). À procura do ensino eficaz. Relatório técnico. Brasília: MEC-DAEB.

Franco, C. \& Bonamino, A. (2001). Iniciativas recentes de avaliação da qualidade da educação no Brasil. Em C. Franco (Org.), Avaliação, ciclos e promoção na educação (pp. 15-28). Porto Alegre: Artmed.

Fukuda, C. C. (2003). O ensino eficaz na educação básica: um modelo descritivo dos fatores de eficácia. Tese de Doutorado, Universidade de Brasília, Brasília.

Goldstein, H. (2001). Modelos da realidade: novas abordagens educacionais. Em C. Franco (Org.), Avaliação, ciclos e promoção na educação (pp. 85-100). Porto Alegre: Artmed.

Goldstein, H., Rasbash, J., Plewis, I., Draper, D., Browne, W., Yang, M., Woodhouse, G. \& Healy, M. (1998). A user's guide to MLwiN. London: Institute of Education.

Hox, J. (2002). Multilevel analysis: techniques and applications. London: IEA.

Instituto Nacional de Estudos e Pesquisas Educacionais Anísio Teixeira - INEP, (2001a). SAEB 2001: Novas Perspectivas. Brasília: Ministério da Educação/INEP.

Instituto Nacional de Estudos e Pesquisas Educacionais Anísio Teixeira - INEP (2001b). SAEB: Relatório Nacional 2001. Brasília: Ministério da Educação/INEP.

Jesus, G. R. de. (2004). Fatores que afetam o desempenho em português: um estudo multinível com dados do SAEB 2001. Dissertação de Mestrado, Universidade de Brasília, Brasília.
Johnson, R. \& Wichern, D. (1998). Applied multivariate statistical analysis (4a ed.). Jersey: Prentice Hall.

Kreft, I. \& De Leeuw, J. (1998). Introducing multilevel modeling. Lodon: Sage Publications.

Lüdke, M. (2001). Evoluções em avaliação. Em C. Franco (Org.), Avaliação, ciclos e promoção na educação (pp. 121-153). Porto Alegre: Artmed.

MEC/INEP (1999). Matrizes Curriculares de Referência: SAEB (2 ${ }^{\text {a }}$ ed.). Brasília: MEC/INEP.

Mello, J. C., Leta, F., Fernandes, A., Vaz, M., Helena. M. \& Barbejat, M. (2001). Avaliação qualitativa e quantitativa: uma metodologia de integração. Ensaio: avaliação e políticas públicas em educação, 9(31), 237-254.

Natis, L. (2001). Modelos lineares hierárquicos: construção e interpretação de escalas de conhecimento. Estudos em Avaliação Educacional. 23, 1-27

Rodrigues, M. M. M. (2002). Instrumentos de avaliação educacional: uma visão pedagógica e psicométrica integradas, estudo das provas do SAEB de Matemática $8^{a}$ série - 1997 e 1999. Dissertação de Mestrado, Universidade de Brasília, Brasília.

Soares, J. F. \& Alves, M. T. G. (2003). Desigualdades raciais no sistema brasileiro de educação básica. Educação e Pesquisa, 29(1), 147-165.

Soares, J. F., César, C. C. \& Mambrini, J. (2001). Determinantes de desempenho dos alunos do ensino básico brasileiro: evidências do SAEB de 1997. Em C. Franco (Org.), Avaliação, ciclos e promoção na educação (pp. 121-153). Porto Alegre: Artmed.

Snijders, T. A. B. \& Bosker, R. J. (1999). Multilevel analysis: An introduction to basic and advanced multilevel modeling. London: SAGE Publications.

Young, D. J., Reynolds, A. J. \& Walberg, H. J. (1996). Science achievement and educational productivity: a hierarchical linear model. The Journal of Education Research, 5(89), 272-278.

Willms, J. D. \& Somers, M. (2000). Family, Classroom, and School Effects on Children's Educational Outcomes in Latin America. School Effectiveness and School Improvement, 12(4), 409-445. 